\title{
BMJ Open Six countries, six individuals: resourceful patients navigating medical records in Australia, Canada, Chile, Japan, Sweden and the USA
}

\author{
Liz Salmi (D) , ${ }^{1}$ Selina Brudnicki, ${ }^{2}$ Maho Isono, ${ }^{3}$ Sara Riggare, ${ }^{4}$ Cecilia Rodriquez, ${ }^{5}$ \\ Louise K Schaper, ${ }^{6}$ Jan Walker (D) , ${ }^{1,7}$ Tom Delbanco $^{1,7}$
}

To cite: Salmi L, Brudnicki S, Isono M, et al. Six countries, six individuals: resourceful patients navigating medical records in Australia, Canada, Chile, Japan, Sweden and the USA. BMJ Open 2020;10:e037016. doi:10.1136/ bmjopen-2020-037016

- Prepublication history for this paper is available online. To view these files, please visit the journal online (http://dx.doi. org/10.1136/bmjopen-2020037016).

JW and TD are joint senior authors.

Received 15 January 2020 Revised 29 June 2020 Accepted 15 August 2020
Check for updates

(C) Author(s) (or their employer(s)) 2020. Re-use permitted under CC BY-NC. No commercial re-use. See rights and permissions. Published by BMJ.

For numbered affiliations see end of article.

Correspondence to

Liz Salmi;

Isalmi@bidmc.harvard.edu

\section{ABSTRACT}

In the absence of international standards, widely differing attitudes and laws, medical and social cultures strongly influence whether and how patients may access their medical records in various settings of care. Reviewing records, including the notes clinicians write, can help shape how people participate in their own care. Aided at times by new technologies, individual patients and care partners are repurposing existing tools and designing innovative, often 'low-tech' ways to collect, sort and interpret their own health information. To illustrate diverse approaches that individuals may take, six individuals from six nations offer anecdotes demonstrating how they are learning to collect, assess and benefit from their personal health information.

\section{INTRODUCTION}

As increasing numbers of nations spend billions on health information technology, what patients might want in this new and rapidly evolving context is often lost or unheard. Many individuals feel stuck, whether in a paper-based system or a health portal to nowhere. ${ }^{12}$ Rhetoric about "patient-centred care' abounds, but only rarely does it extend to accessible medical records in primary, specialty and even hospital care.

In the spring, 2017, healthcare teams from 11 countries convened at a Salzburg Global Seminar in Austria to examine how patients might engage more actively in their care with the help of transparent electronic medical records that are evolving globally. ${ }^{3}$ More than 60 participants gathered, representing diverse points of view-clinicians, researchers, policy-makers, social scientists and patients. The participants discussed the untapped potential of electronic medical records and how secure systems might help patients and clinicians share personal health information. In the absence of international standards, the degree to which individual patients participate in their care is largely moulded by widely differing attitudes, laws and interpretations of laws, ${ }^{45}$ and medical and social cultures. However, patients are increasingly convening across cultures, and patient advocates are learning to push the professions to open doors that until recently have been firmly shut.

In this article, six Seminar participants with different healthcare needs provide a personal snapshot of what it is like to be a patient and read records in their respective countries. Each reported on salient characteristics of the country's health records systems (table 1) and considered five questions (Sidebar) as they wrote about their experience livingand thriving-in evolving digital climates.

Sidebar: each patient/care partner author was prompted to think about these 5 questions.

\section{Questions}

- As a patient, what information can you (and can you not) access in your medical record?

- How has access/lack of access impacted your medical decision-making?

- How are patients in your country 'hacking' (modifying) traditional/approved methods of access to medical information in search of improved health outcomes?

- How are patients in your country redefining their roles, including the words 'patient' and 'health outcomes'?

- How might medicine profit from listening carefully to patients and their evolving roles?

\section{PERSPECTIVES}

Sweden: knowledge is power

Sara Riggare

In the mid-1980s, I discovered in my early teens that something was not right with my body. At times, my muscles became rigid and 


\begin{tabular}{|c|c|}
\hline Country & Description \\
\hline Australia & $\begin{array}{l}\text { In early } 2019 \text {, the Australian government assigned citizens a secure, online health record. My Health Record } \\
\text { aspires to house summary information uploaded from encounters with the health system nationwide. }{ }^{5}\end{array}$ \\
\hline Canada & $\begin{array}{l}\text { In Canada, } 85 \% \text { of family practice physicians, and } 79 \% \text { of specialist physicians report using an electronic } \\
\text { medical record. }{ }^{15} \text { However, only } 22 \% \text { of Canadians can access portions of their medical records } \\
\text { electronically. No patients have access to their entire records. }{ }^{16}\end{array}$ \\
\hline Japan & $\begin{array}{l}\text { In Japan, health systems, hospitals and small practices work with various electronic health record systems. } \\
\text { Citizens have the legal right to request medical records, but most are unaware of this opportunity. The } \\
\text { majority of citizens do not have digital access to their health records, although apps are available that display } \\
\text { lists of prescriptions available at pharmacies. }{ }^{19}\end{array}$ \\
\hline The USA & $\begin{array}{l}\text { About } 80 \% \text { of doctors, and nearly all hospitals in the USA use electronic health records. }{ }^{21} \text { In } 2017 \text {, a little over } \\
\text { half of patients reported offers of online access to their records, either by their providers or by their insurers. } \\
\text { Among them, a little more than half registered on their health systems' secure portals and viewed their } \\
\text { records at least once. }{ }^{22} \text { Health providers control what patients can and cannot access through these portals. }\end{array}$ \\
\hline
\end{tabular}

tense, making me slow and clumsy, especially during repetitive movements such as brushing my teeth. I learnt I have a form of Parkinson's disease, and for more than 30 years now, I have been living with this condition.

My overall strategy? Care for myself. Without medications, my body does not function, but my doctor has no way of knowing if and how I take medications he prescribes. Until recently, my neurologist did not provide online access to my healthcare records, but I collected them all on paper and placed them in a binder. I review open access scientific publications online, looking for new research results that might benefit me. I combine what I learn with data and observations I collect myself, all of which enables me to understand and better manage my condition.

Some years back I came across a new study documenting effects of a drug under evaluation for freezing of gait, one of my symptoms. I emailed the article to my neurologist. We agreed that it was worth exploring, and I got a prescription. Soon we both concluded that it did indeed improve my gait.

Working with a doctor this way is not unique to me. In a recent survey, $68 \%$ of Swedish respondents with Parkinson's disease saw their neurologist for an hour or less annually. ${ }^{6}$

As patients, we take prime responsibility for managing our own health. Meanwhile, our neurologists can attend to people who need more help.
Chile: my arthritis, in bits and pieces

\section{Cecilia Rodriguez}

I have rheumatoid arthritis, and when I go to the hospital for a day to get my intravenous medication, they print a copy of the visit and give it to me. Often it is handwritten and hard to read. Beyond that, I can get some exam results from the clinic website, but only with a special code for a one-time download. I cannot compare results of my exams in one place, so I print them or save them on my computer in case I need to look at them again. I want to make my own decisions, so this has meant getting lots of paper together. But often I cannot find the right one. I know I put it somewhere!

This year, my mom gave me a notebook for my birthday. It had the medical information she had saved from the first 14 years of my life! It might sound crazy or unnecessary, but it is important for me. I was once admitted for pericarditis (a swelling of the membrane surrounding the heart). Afterwards, I could not remember my actual diagnosis; I kept forgetting things I wanted to tell my doctor and he kept telling me things that were so important. I laugh about this present from my mom, but it makes me feel safe to have my medical story together again.

\section{Japan: can technology help patients become more active} agents in their care?

Maho Isono, PhD

I think medicine in Japan is profiting from listening carefully to patients. As anthropologist Arthur Kleinman 
pointed out, the community is the biggest space in which patients deal with illness. ${ }^{7}$ Today, this space is changing and growing rapidly because of the expansion of online platforms where patients can take in and mingle knowledge from scientific medicine and traditional medicine. Then they establish their own understanding and management for their illness. Patients move beyond being objects of biomedicine to become active agents who choose how and when to move around within the various sectors of health and illness.

Numerous communities organised by patients with various diseases exist in Japan. One remarkable approach to achieve patient-centred medicine is tojisha-kenkyu. Kenkyu means study, investigation and research. Tojisha refers to interested persons, disabled persons themselves or patients themselves. In tojisha-kenkyu, tojisha share their everyday problems with one another, then analyse and discuss how to deal with them. This is noteworthy since, rather than getting advice from medical professionals, tojisha find solutions or a way of managing problems from the perspectives of tojisha themselves. Founded initially in 2001 by the social welfare facility Bethel House in Hokkaido, it has become a prominent activity of people with mental disorders. Different from self-support groups, individuals conducting tojisha-kenkyu share their findings with the public. This has been particularly significant for people with mental disorders, since in our country their experiences have often been suppressed and hidden. ${ }^{8}$ Tojisha-kenkyu has been further developed. For instance, tojisha and researchers from fields such as cognitive science and robotics are working together to explore the scientific validity of the hypotheses generated by tojisha-kenkyu. ${ }^{9}$ In light of the purpose of this paper, tojisha-kenkyu made it possible for tojisha to create, accumulate and update their own record of everyday problems which is not restructured by medical gaze.

Some patients are trying and reporting that new technologies are helping. However, patients occasionally report that technology is increasing anxiety, rather than helping. In my medical anthropological research, I interviewed an individual whose atrial fibrillation (irregular heartbeat) comes and goes. He bought a micro ECG machine to keep track of his pulse. He tried to find a pattern in his irregular pulse, but over time could'nt make one out. He did not enjoy watching his irregular pulses every day, and eventually he stopped wearing the device. Our engaged patients are still discovering how to strike the right balance in patient empowerment.

\section{Canada: from access to control of our own health data Selina Brudnicki}

I saw first-hand the hardships my late mother experienced obtaining copies of her records. She had to navigate her health and share information with her care team. She underwent breast cancer treatment at several facilities and learnt to interpret her results with the help of her doctors. I kept her 'big binder' of results. It includes pathology and diagnostic imaging reports, and even a few oncologists' notes. Therein lies also my mother's own handwritten note: '[The doctor's] report does not seem correct. I always mention 'pain,' not discomfort. I kept complaining about a new pain'. One year too late, a second opinion and review of her medical notes revealed that she and her doctor were not on the same page. There was evidence that her cancer had already spread to her lungs and liver. She died soon thereafter.

I am a senior manager at University Health Network, Toronto, and my colleagues and I work closely with patients to understand their needs and priorities so they can better manage their health. Co-designed with patients, care partners and staff, we co-created a secure website that enables patients to see their appointment schedules, test results, pathology and diagnostic imaging reports, and clinical notes at the same time they become available to their care team. There are links to patient education resources, and patients may share their health record with others. After a year, $94 \%$ of patients reported improved patient experience. They felt better prepared for appointments, for decisions they needed to make and reported improved communication and management of their care. ${ }^{10}$

Today, patients want visibility and transparency into all their health data, but they face a large cultural divide: health information custodians and care providers in our country currently control what, when and whether patients can access their own data. In response, we collaborated with patients, their care partners, government and industry subject matter experts to advance a new paradigm in which patients have the ability to authorise, revoke and monitor secondary use of their data. That way they can both take control over their health data and consent to sharing their data with trusted sources.

\section{Australia: dad is old and ill. What may his future hold? Louise K Schaper, PhD}

Today, dad sent me a picture of prescription medications that would fill two shoe boxes. He has been 'shopping up' big, in preparation for a 2-month vacation. I suspect it will be his last. Ever the stoic head of household, dad tells us he is fine, and while we know that's untrue, we do not know if he is a bad liar or in denial. Every time he is prescribed a new drug or there is a new symptom, mum phones to fill me in. My parents do not have the internet, and since I am the one with a health degree, I get asked to interpret medical symptoms and pill prescriptions.

Given dad's deteriorating health, I was desperate to see what his doctors actually think, and dad granted me proxy access to his My Health Record (MyHR). Now I can help interpret information and often put his and my family's mind at ease. But he does not tell his medical team about how regularly his blood pressure goes to levels that could kill most people. He 'wouldn't want to bother them'.

I learnt from dad's record that he is on 12 different prescription medications, and there is also an audit trail of every medical appointment he has had. But it is limited to the date and name of the clinician only. Basically, the 
information in MyHR is limited to what is in a government database of prescriptions and appointments, information we already have. Dad's clinicians are not uploading any of his clinical notes, and neither are the pathologists. He could actually request more information, but I can hear dad's voice in my head: 'No. The doctor is too busy and I don't want to make a fuss'.

So meanwhile, my family and I are none the wiser. Our hopes remain unrealied: to uncover information that could help dad change his behaviours or reveal errors (if he would dare point them out to his doctors). For now, I am left with a question that gnaws at me: 'If they're denied access to their own health information, how can patients have agency over their own health?".

\section{The USA: even the activist struggles}

Liz Salmi

I was diagnosed with an astrocytoma (a slow-growing brain cancer) 1 week after my 29th birthday, and since then I have lived in a world of uncertainty: 20 more years, or 20 more months?

My way of coping with uncertainty? Understand as much as I can about my condition and plan for treatment. For this, I have found the patient portal a trusted sidekick. After surgeries, seizures, appointments and tests, the patient portal is where I turn to be reminded of the growing narrative, that is, my medical history.

One day, after a few months of chemotherapy, I recognised a pattern in the laboratory results available on my patient portal. It showed me when I was at risk for thrombocytopenia and would need to delay treatment. Thereafter, instead of waiting for permission to start my next round of oral chemotherapy, I would email my doctor:

\section{Dear Dr. S,}

My lab work appears to be the same as last month. Please authorize a refill for temozolomide. Per the plan we discussed during our last visit, I will pick up the prescription on my way home from work tomorrow and begin my next round of chemo on Monday.

She agreed with this process, and my ability to turn information into knowledge (with guidance from my doctor) returned a sense of autonomy to me at a time when I felt I had almost no control over any other aspect of my health.

Positive reinforcement from my doctors has moulded me into the proactive patient I am today. However, even with widespread availability of patient portals, patient activists like me continue to struggle to gain access to the most important part of our medical records: the doctor's note. In the USA, we have had the right by law for more than 20 years to request and receive copies of our full medical records-including our doctors' notes. But these requests take time and effort, and costs can be involved. ${ }^{11}$ I once requested a copy of my record and finally got it on a DVD. Had I asked for a paper copy, I would have had to pay $\$ 725.40$ out of my own pocket. All that just to own what is inherently mine! Today, almost $15 \%$ of Americans have gained access to clinical notes through a portal, but the actual 'read rates' of notes remain low, virtually across the board. ${ }^{12}{ }^{13}$ It is not easy to change long-standing culture and habits!

\section{CONCLUSION}

As these anecdotes demonstrate vividly, the global impact of electronic medical records varies widely and will no doubt continue to do so for a very long time. The emerging technologies that will further define and refine medical records need to reflect different cultures, individual sensibilities, socioeconomic factors and myriad other phenomena. But the perspectives we display have a common denominator: persistent resourcefulness as individuals work to bridge gaps in their personal health information.

Some describe patient engagement as the 'blockbuster drug' of the 21st century, but how many will want to engage in ways described by those featured in this paper? ${ }^{14}$ Are large numbers of people, perhaps even most people, capable of becoming so resourceful? We suggest the answer may be 'yes'. We suspect the potential is there, with the caveat that patients become truly engaged only when they have a more complete picture of their own health.

Transparent medical information is spreading. While in some cultures different views prevail, most nations agree today that patients have a right to access their own health information. Offering patients ready access to their own medical records makes sense, because patients (and their care partners) need abundant information in order to engage optimally in their care, while regaining and retaining autonomy in their lives.

\section{Author affiliations \\ ${ }^{1}$ Department of General Medicine, Beth Israel Deaconess Medical Center, Boston, \\ Massachusetts, USA \\ ${ }^{2}$ University Health Network, Toronto, Ontario, Canada \\ ${ }^{3}$ International University of Health and Welfare, Ōtawara, Japan \\ ${ }^{4}$ Health Informatics Centre, Karolinska Institutet, Stockholm, Sweden \\ ${ }^{5}$ Fundacion Me Muevo, Santiago, Chile \\ ${ }^{6}$ Health Informatics Society of Australia, Victoria, South Australia, Australia \\ ${ }^{7}$ Harvard Medical School, Boston, Massachusetts, USA}

Twitter Liz Salmi @TheLizArmy and Selina Brudnicki @sbrudnicki

Acknowledgements The authors wish to thank the alumni and staff of Salzburg Global Session 553, 'Toward a Shared Culture of Health: Enriching and Charting the Patient-Clinician Relationship', for their leadership on this topic.

Contributors All authors contributed substantially to the manuscript. TD, LS and JW conceived the idea and design, and drafted and critically revised the text. LS, SB, MI, SR, CR and LKS developed country-specific content.

Funding This work was supported by the Salzburg Global Seminar, the John F. Keane \& Family Foundation, and the Wang Foundation.

Competing interests None declared.

Patient consent for publication Not required.

Provenance and peer review Not commissioned; externally peer reviewed.

Open access This is an open access article distributed in accordance with the Creative Commons Attribution Non Commercial (CC BY-NC 4.0) license, which 
permits others to distribute, remix, adapt, build upon this work non-commercially, and license their derivative works on different terms, provided the original work is properly cited, appropriate credit is given, any changes made indicated, and the use is non-commercial. See: http://creativecommons.org/licenses/by-nc/4.0/.

\section{ORCID iDs}

Liz Salmi http://orcid.org/0000-0003-3798-7438

Jan Walker http://orcid.org/0000-0001-9366-1200

\section{REFERENCES}

1 Krumholz $\mathrm{H}$. The unfortunate truth about getting your medical records Forbes; 2018. https://www.forbes.com/sites/harlankrumholz/ 2018/10/05/the-unfortunate-truth-about-getting-your-medicalrecords/amp/?_twitter_impression=true

2 Topol E, Salmi L, Twitter. Portal to nowhere.

3 Delbanco T, Esch T. Toward a shared culture of health: enriching and charting the Patient-Clinician relationship session 553. Salzburg Global Seminar; 2017. https://www.salzburgglobal.org/multi-yearseries/health/pageld/session-553.html [Accessed 24 Oct 2019].

4 Krumholz HM. Opinion: It Should Be Easier To Access Your Medical Records : Shots, 2019. Available: https://www.npr.org/sections/ health-shots/2019/08/28/754725843/opinion-its-your-right-to-seeyour-medical-records-it-shouldn-t-be-this-hard-to- [Accessed 24 Oct 2019].

5 Australian Government, Australian Digital Health Agency. My health record: control your health information securely, in one place. Available: https://www.myhealthrecord.gov.au/ [Accessed 24 Oct 2019].

6 Riggare S, Höglund PJ, Hvitfeldt Forsberg $\mathrm{H}$, et al. Patients are doing it for themselves: a survey on disease-specific knowledge acquisition among people with Parkinson's disease in Sweden. Health Informatics J 2019;25:91-105.

7 Kleinman A. Patients and healers in the context of culture: an Exploratio of the Boderland between anthropology, medicine, and psychiatry. Berkeley, CA: University of California, Berkeley, 1980.

8 Ishihara K. Tojisha Kenkyu no Kenkyu. Tokyo, Igakushoin, 2013.

9 Kumagaya Laboratory. Facilitation and verification of Tojisha-Kenkyu through an interdisciplinary approach, 2020. Available: https://www. rcast.u-tokyo.ac.jp/content/000009298.pd
10 Brudnicki S, Bishop L, Bakas V. Delivering results as patients access their online medical records. Vancouver, CA EHealth; 2018.

11 Lye CT, Forman HP, Gao R, et al. Assessment of US Hospital compliance with regulations for patients' requests for medical records. JAMA Netw Open 2018;1:e183014.

12 OpenNotes ${ }^{\circledR}$. OpenNotes MAP. Available: https://www.opennotes. org/join/map/ [Accessed 25 May 2020].

13 Santa J, Wachenheim D, Chin H, et al. Implementing OpenNotes: improving patient access to notes on patient portals 2018.

14 Chase D. Patient engagement is the Blockbuster drug of the century. Forbes 2014:2012-5

15 Leaver $\mathrm{C}$. Use of electronic medical records among Canadian physicians, 2017. Available: https://www.infoway-inforoute.ca/en/ component/edocman/resources/reports/benefits-evaluation/33622017-cma-workforce-survey-digital-health-results [Accessed 25 Jun 2020].

16 Canada Health Infoway. Connecting patients for better health, 2018. Available: https://www.infoway-inforoute.ca/en/component/ edocman/3564-connecting-patients-for-better-health-2018/viewdocument?Itemid=101 [Accessed 25 Jun 2020].

17 Martinez-Gutierrez MS. Income and health insurance type in Chile : Effects on health and health. Berkeley Cent Lat Am Stud Univ California; 2014: 2010-3.

18 Taylor EA, Fischer SH, Gracner T, et al. Current Efforts to Implement Health IT in Chile. In: Developing a strategic program for Chilean health information technology: environmental scan and key informant interviews, 2016: 10-19.

19 NPO Japan Medical Network Association. What is the Millennial medical record? Available: http://www.gehr.jp/about/index.html [Accessed 24 Oct 2019].

20 Inera.se. Inera statistics. Available: https://www.inera.se/aktuellt/ statistik/ [Accessed 25 Jun 2020].

21 Secretary of Health and Human Services. Report to Congress on health it progress: examining the HITECH era and the future of health it; 2016. http://dashboard.healthit.gov/report-to-congress/2016report-congress-examining-hitech-era-future-health-informationtechnology.php

22 Patel V, Johnson C, The Office of the National Coordinator for Health Information Technology. Individuals' Use of Online Medical Records and Technology for Health Needs, 2018. Available: https://www. healthit.gov/sites/default/files/page/2018-03/HINTS-2017-ConsumerData-Brief-3.21.18.pdf [Accessed 29 Jul 2019]. 